\title{
SYNTHESIS, CHARACTERIZATION AND EFFECT OF MCROSTRUCTURE ON SLURRY EROSION RESSTANCE OF CAST Fe-TIC COMPOSITES
}

\section{M.K.Manoj ${ }^{1}$, R.K.Galgali ${ }^{2}$,S.K. Nath ${ }^{3}$, and S. Ray ${ }^{4}$}

${ }^{1}$ Research Scholar, Department of Metallurgical and Materials Engineering, II.TT Roorkee India

${ }^{34}$ Department of Metallungical and Materials Engineering, IIITT Roorkee India, E-mail: indiafmt @iirtemetin

${ }^{2}$ RRL Bhubaneswar India

\begin{abstract}
$\mathrm{Fe}$-TiC composites containing varying amounts of TiC particles have been synthesized by casting route. This is achieved by carbothermic reduction of ilmenite ore along with varying amount of steel scrap in a plasma reactor in one step. Three composites containing TiC particles varying from 4 to $9 \%$ have been prepared. Microstructures of composites show TiC particles in the matrix of transformed ledeburite (pearlite and cementite). Distribution of TiC particles has been found to be satisfactorily uniform and size varies from 2 to 3 microns. Composite having $9 \mathrm{vol} \%$ has shown non-uniform distribution of TiC particles and size variation from 2 to 8 microns. In 9\% TiC composites, graphite flakes have also been found. It has also been observed that composite having TiC content greater than $9 \%$ becomes very difficult to cast because of higher viscosity of the melt during pouring. These composites have been characterized by hardness measurement, optical microscopy, FESEM, and XRD. Hardness of these composites has been found to depend on vol.\% of TiC and on the nature of the matrix. Slurry erosion test has shown higher erosion resistance in castings with lesser porosity, optimum vol\% of TiC, and in the matrix of transformed ledeburite. Presence of graphite in the matrix lowers slurry erosion resistance of the cast composite.
\end{abstract}

Keywords: Fe-TiC composite, Carbothermic reduction, Graphite, Sluny wear.

\section{Introduction}

Fe-TiC composites have emerged as one of the most important tribological materials due to its high hardness and adequate toughness (Kattamis et al. 1990). These composites have been found to retain properties at elevated temperatures and also have superior corrosion resistance. Fe-TiC composites are traditionally made by powder metallurgy method and find applications in the making of press tools, in fluid pump as a seal ring, in waste-derived fuel plants, pneumatic pipes and duct and also in mining and paving industries (Rai et al. 1999). A lot of interest has been generated in the recent past in the processing of $\mathrm{TiC}$ reinforced ferrous composites by solidification route as compared to powder metallurgy route (Kattamis et al. 1990, Terry et al. 1991, Rai et al. 1994). Synthesis of composites by powder metallurgy route is relatively more expensive and imposes size limitations on components. High production cost and risk of contamination of the interface of TiC particle with the matrix are also drawbacks of powder metallurgy route. This paper therefore focuses only on cast in situ Fe-TiC composites.

Two types of Fe-TiC composites are being processed: (i) surface composites and (ii) bulk composites. In situ production of Fe-TiC surface composites has been reported by (Wang et al. 1999), by cast sintering technique by (Wang et al. 1999), tungsten-inert gas welding technique by (Wang et al. 2006), and themal spray by (Smith et al. 1988). Bulk in situ Fe-TiC composites have been reported by (Kattamis et al. 1990, Terry et al. 1991, Rai et al. 1994, and Galgali et al. 1998, and Rai et al. 1999). The work of (Galgali et al. 1998) involves synthesis of Fe-TiC master alloy by carbothermic reduction of ilmenite ore in a plasma reactor. This master alloy was then used to develop TiC reinforced ferrous alloy. In the present work in situ Fe-TiC cast composites have been made by carbothermic reduction of ilmenite ore along with steel scrap in a plasma reactor in one step followed by casting in sand mould. Fe-TiC composites having $\mathrm{TiC}$ content up to 9 vol\% have been cast successfully. As TiC content increases beyond 9 vol\% its pouring becomes very difficult due to high viscosity of the melt. Metallographic studies, XRD, SEM/EDAX analysis have been used to characterize these composites. Further slurry wear test has been carried out to determine the wear resistance of these composites and these results are compared with that of white cast iron.

\section{Experimental Procedure}

\subsection{Preparation of Fe-TiC composites}

Fe-TiC composites have been prepared in situ in $35 \mathrm{~kW}$ direct current transferred arc plasma reactor by carbothermic reduction of ilmenite ore concentrate, graphite powder reductant, chemical reagent-grade oxides and fluorides as fluxes and steel scrap followed by casting in sand mould. In different heats varying amounts of low carbon 
steel scrap has been used to prepare Fe-TiC composites of varying amounts of TiC particles in ferrous matrix. The raw materials used are ilmenite ore concentrate, graphite powder, flux (silica, calcia, magnesia and calcium fluoride) and steel scrap (C-0.2\%). The particle size of ilmenite ore concentrate is about $1 \mathrm{~mm}$ and graphite powder size is in the range of $150-250$ microns. Ilmenite ore analysis is found to be $50.2 \% \mathrm{TiO}_{2}, 34.1 \% \mathrm{FeO}$, $12.8 \% \mathrm{Fe}_{2} \mathrm{O}_{3}$, and rest other oxide like $\mathrm{SiO}_{2}, \mathrm{Al}_{2} \mathrm{O}_{3}, \mathrm{ZrO}_{2}, \mathrm{MnO}$ and $\mathrm{MgO}$. Relative amounts of raw materials (charge) used for making composites are given in Table 1. A basicity i. e., $(\mathrm{CaO}+\mathrm{MgO})\left(\mathrm{SiO}_{2}+\mathrm{Al}_{2} \mathrm{O}_{3}\right)$ ratio has been maintained in the range of 1-1.5. 20 to 40 pct by volume $\mathrm{H}_{2}$ is added to plasma forming gas argon. The flow of argon is regulated at 1.6 litres per minute. The charge is reduced between the graphite cathode and anode electrodes arranged in a vertical configuration in the pot reactor whose power supply is given by a DC arc welding power source. The arc voltage and current were maintained at 45 to 50 volts and 300 ampere respectively during the experiment. The bottom electrode which is the anode is fixed and the arc plasma stabilization is done through the adjustment of the top electrode (cathode) that is actuated by a rack and pinion mechanism. The hearth of the reactor is provided with a tap hole and a graphite spout is connected to it for tapping both metal and slag. The details of plasma reactor, its working and process variables are given in the paper of (Galgali et al. 1998).

Table 1: Amount of ilmenite ore, steel scrap and graphite powder for preparation of four composites.

\begin{tabular}{|c|c|c|c|}
\hline Composite & Ilmenite (g) & Graphite (g) & $\begin{array}{c}\text { Steel Scrap(g) } \\
\text { (For dilution) }\end{array}$ \\
\hline A & 106 & 50 & 731 \\
\hline B & 165 & 75 & 725 \\
\hline C & 240 & 95 & 655 \\
\hline
\end{tabular}

Three Fe-TiC composites containing 4, 6 \& 9\% TiC particles by volume have been prepared by above stated method. These composites are named as Composite-A, Composite-B, and Composite-C respectively. These composites have been cast in a sand mold and size of cast samples is $10 \mathrm{~mm} \times 6 \mathrm{~mm} \times 150 \mathrm{~mm}$.

Fig. 1 shows the microstructure of a Fe-TiC master alloy when small amount of steel scrap has been added for dilution. The microstructure consists of white TiC particles embedded in the matrix of pearlite and cementite. Large amount of graphite flakes is also present.

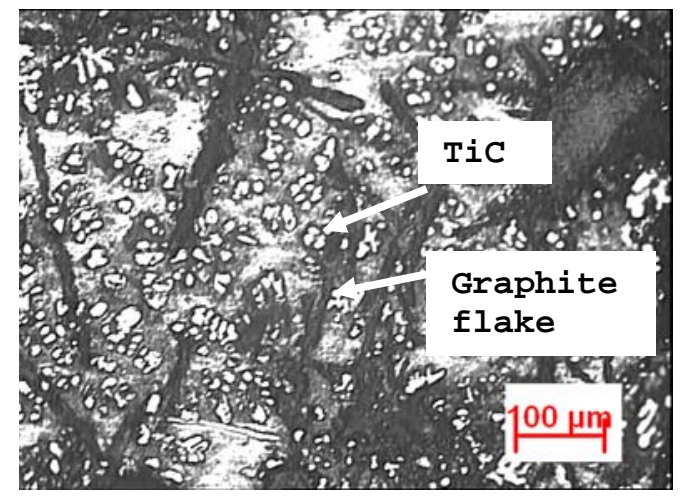

Fig. 1: Microstructure of Fe-TiC master alloy.

\section{Characterization of Fe-TiC composites}

Fe-TiC composites have been characterized by optical and scanning electron microscopy in terms of size, shape and distribution of TiC particles in the matrix. Samples of size $10 \mathrm{~mm}$ x $6 \mathrm{~mm}$ x $6 \mathrm{~mm}$ have been cut from the cast composite bars. X ray diffraction analysis of Composite-A has been carried on Bruker AXS D-8 Advance diffractometer (Germany) to determine the presence of $\mathrm{TiC}$ and is shown in Fig.2. Presence of TiC particles is further confirmed by SEM/EDAX analysis using Field Emission Scanning Electron Microscope (FEI, Quanta 200F, Czech Republic) with EDAX Genesis software attachment. Vickers hardness measurements are carried at $30 \mathrm{~kg}$ load. Densities of these composites have been determined by Archimedes principle. 


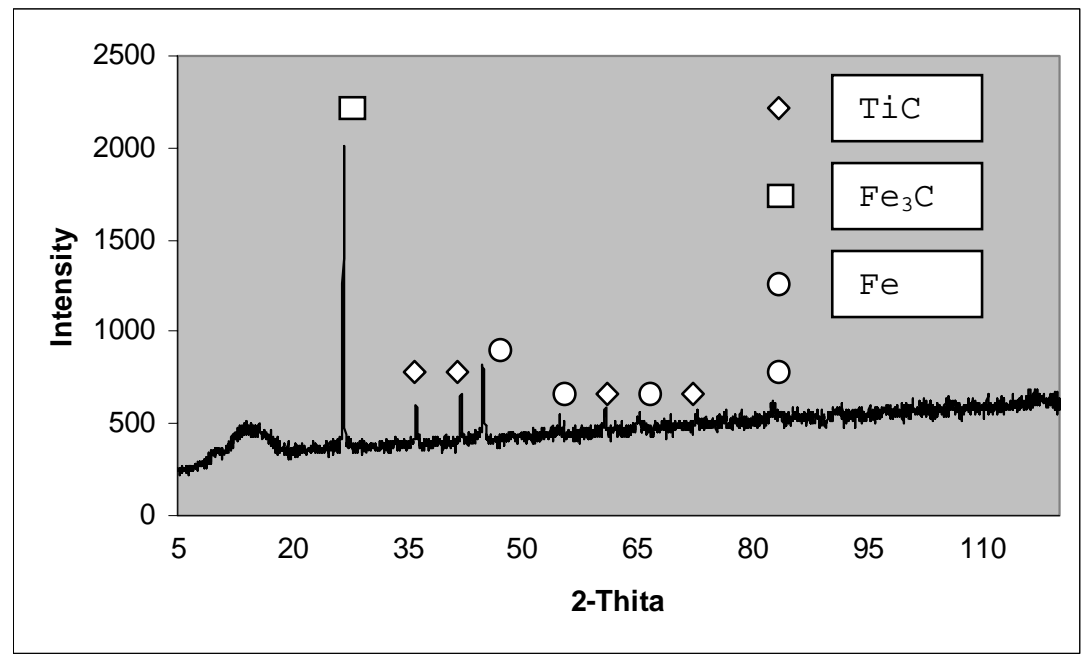

Fig. 2: X-ray diffractograph of Composite-A.

Samples for slurry erosion test of these composites have been prepared in size of $10 \mathrm{~mm} \mathrm{X} 6 \mathrm{~mm} \mathrm{X} \mathrm{4mm.} \mathrm{The} \mathrm{slury}$ contains $25 \mathrm{wt} \%$ sand particles in fresh water. Sieve analysis of silica sand has been carried out and is shown in Table 2. For sluny erosion test, samples have been suspended in the slury with the help of a steel rod which rotates in the slury. The schematic diagram of the slumy erosion testing machine is shown in Fig. 3. The test has been carried out at $800 \mathrm{rmm}$. The total duration of the test is 48 hours and after every 8 hours, weight loss in samples has been determined. Finally specific weight loss (weight loss per unit surface area) has been determined.

Table 2: Sieve analysis of silica sand used for slunry erosion test.

\begin{tabular}{|c|c|}
\hline Mesh No. & \% of Sand Particle \\
\hline+60 & 1.3 \\
\hline$-60+80$ & 14.2 \\
\hline$-80+100$ & 77.6 \\
\hline$-100+150$ & 1.2 \\
\hline$-150+200$ & 2.2 \\
\hline$-200+300$ & 3.5 \\
\hline
\end{tabular}

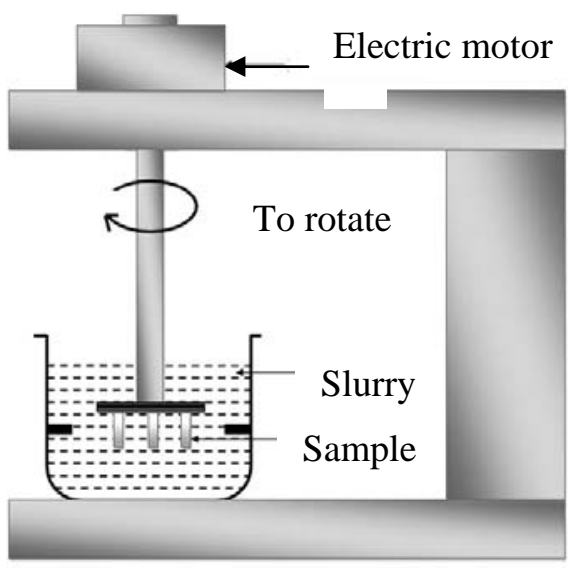

\section{Results and Discussion}

Fig.3: Schematic diagram of the slurry erosion test

\subsection{Optical, SEM and XRD studies}

Optical micrographs of Composite-A, Composite-B, and Composite-C are shown in Figs. 4a-c. The volume fractions of TiC particles of these composites have been determined by quantitative metallographic software in computer interfaced Zeiss Axiovert 200 MAT inverted optical microscope and found to be $4 \%$, 6\%, and 9\% respectively. These composite have also been examined under scanning electron microscope (Leo 435VP, U. K) and micrographs are given in Figs. 5a-c respectively.

Composite-A contains 4 vol\% of TiC particles. With the help of arrow and marker phases have been marked in the micrographs. The shape of TiC particle is found to be rectangular and size is of 2 to 3 microns. Distribution 
of these particles is uniform at some places and segregated at other places. The matrix contains pearlite (black region) and cementite (white region) in the form of dendrite. Composite-B contains 6 vol\% TiC particles. Size and shape is similar to the composite-A. TiC particle distribution is similar to composite-A. Matrix contains pearlite and cementite. No graphite flakes have been observed in these composites. At one place pearlite is clearly resolved into ferrite plus cementite plates.

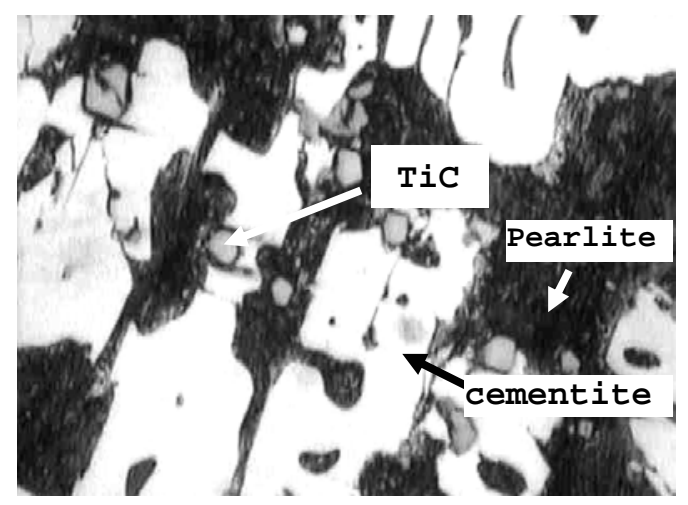

(a)

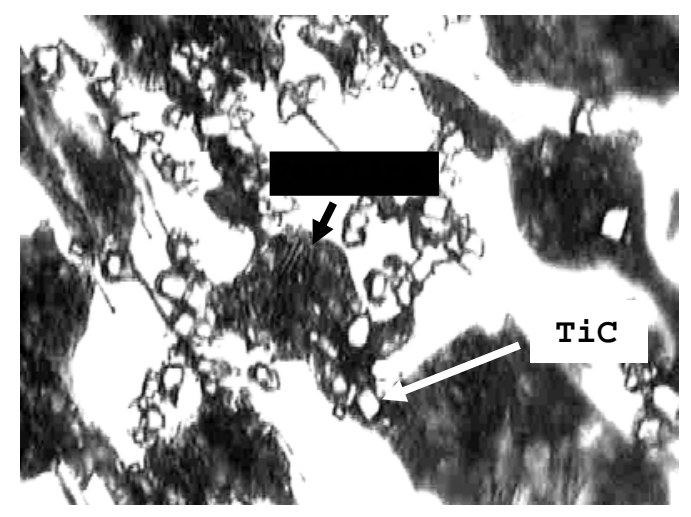

(b)

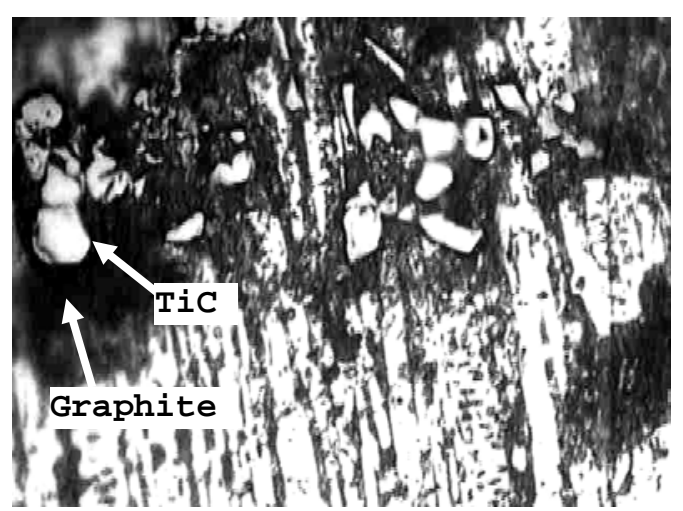

(c)

Fig. 4: Optical micrograph of composites (a) Composite- A (1600x) (b) Composite- B (1600x) (c) Composite C (1600x).

Composite-C is different from others in respect of size and distribution of TiC particles. Here particles are of larger size up to 8 microns and its distribution is not uniform rather segregated. The matrix consists of pearlite, cementite plates and contains some graphite flakes.

\subsection{SEM/EDAX of Composites}

TiC particles in the composites have been identified using SEM/EDAX. Fig. 6a shows SEM micrograph and elements present in the particles marked as "+” sign are shown in Fig. 6b.

\subsection{Co-relation between densities and microstructure}

Densities of these composites have been determined by specific gravity bottle and are shown in Table 3 . Composite-C show lowest density because of presence of carbon in free form (graphite) plus porosity developed during casting. Composite-A, and Composite-B have higher densities because carbon is present in the form of cementite plus porosity is not observed. White cast iron is taken for the purpose of comparison and does not contain TiC particles and graphite flakes. 


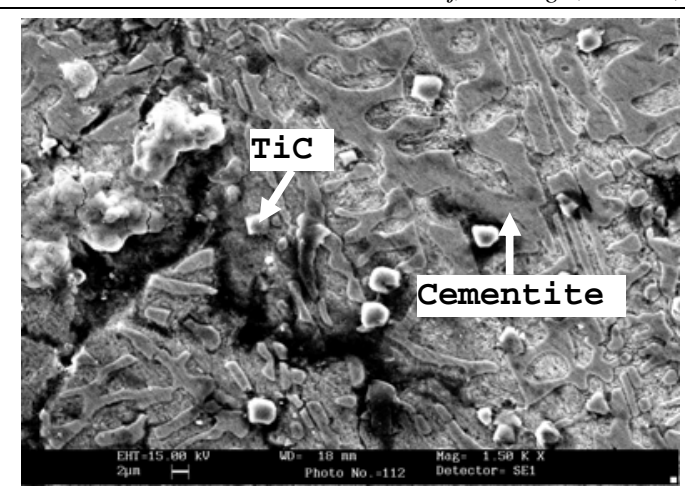

(a)

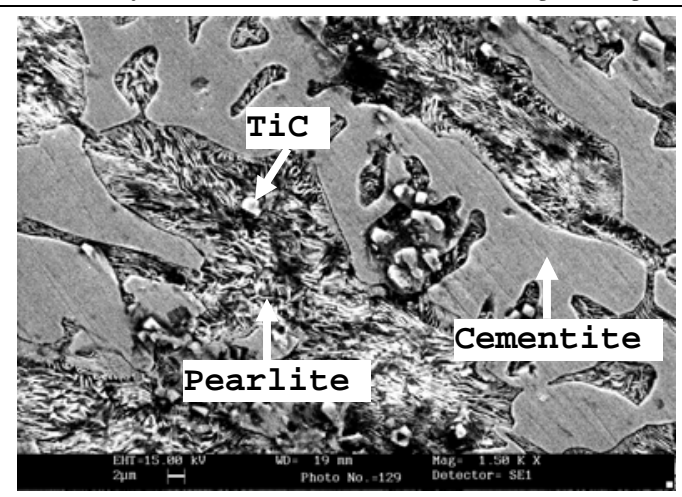

(b)

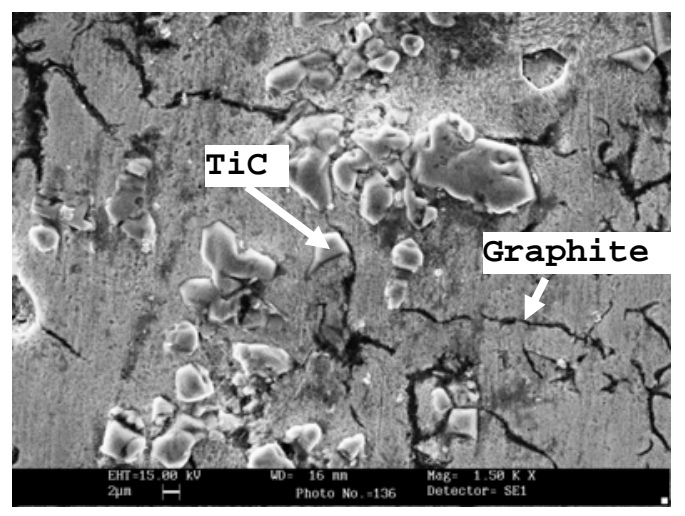

(c)

Fig. 5: SEM Micrographs of Composites (a) Composite-A (1500 x) (b) Composite-B (1500x) (c) Composite-C (1500x)

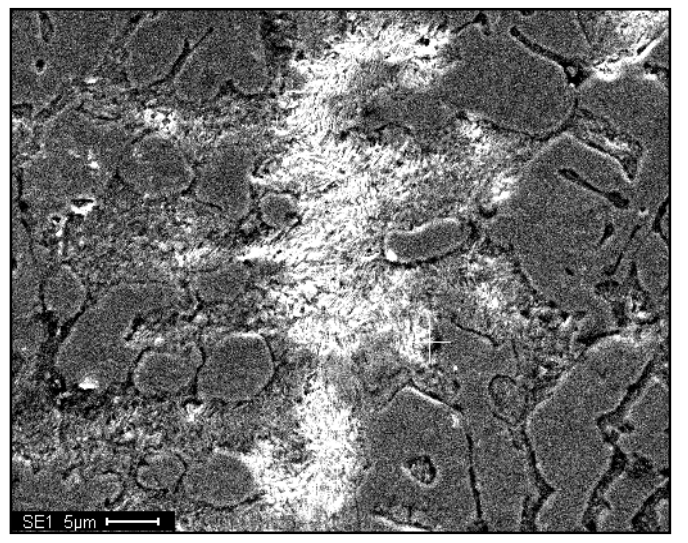

(a)

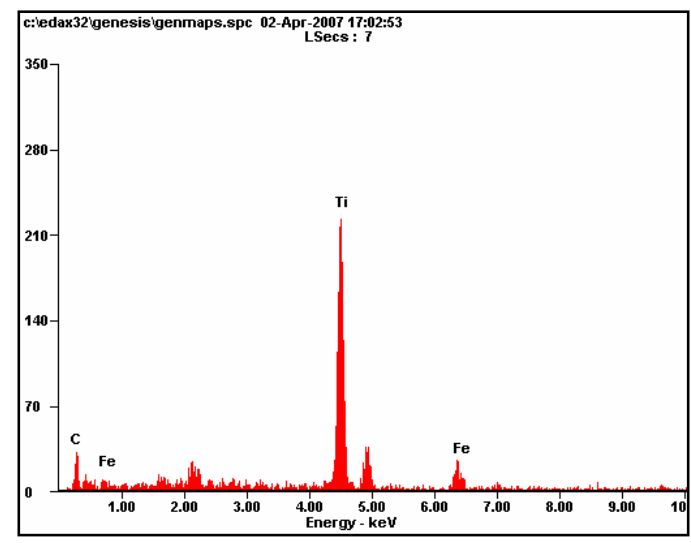

(b)

Fig. 6: SEM/EDAX of Composite-A.

\subsection{Hardness Measurement}

Vickers hardness of these composites has been determined at $30 \mathrm{~kg}$ load and hardness data are given in Table 4 . Hardness of composites increases as TiC content increases in the composites as $\mathrm{TiC}$ is a very hard phase and has hardness 1800 VHN. If carbon is present in the form of graphite then it reduces the hardness of the composites. On the other hand combined form of carbon (cementite) increases the hardness of the composite as $\mathrm{Fe}_{3} \mathrm{C}$ (cementite) is a very hard phase having hardness 1100 VHN. Presence of graphite flakes in Composite-C causes decrease in hardness (216 VHN) as compared to Composite-B and Composite-C. Composite-B and composite-C 
have shown hardness 622 VHN and 635 VHN respectively and this is much higher than the hardness of white cast iron which is only $456 \mathrm{VHN}$. As TiC content of composite increases, porosity of composite also increases because of higher viscosity of melt during pouring. Composite-C ( $9 \% \mathrm{TiC})$ contains graphite flakes as well as porosity. TiC particles distribution is also not uniform in the composite.

Table 3: Densities of composites and white cast iron

\begin{tabular}{|c|c|}
\hline Composite & Density(g/cc) \\
\hline A & 7.62 \\
\hline B & 7.60 \\
\hline C & 7.15 \\
\hline (White cast iron) & 7.65 \\
\hline
\end{tabular}

Table 4: Hardness of composites

\begin{tabular}{|c|c|c|}
\hline Composite & Vol. \% of TiC & $\begin{array}{c}\text { Vickers hardness } \\
\text { VHN }\end{array}$ \\
\hline A & $4 \%$ & 622 \\
\hline B & $6 \%$ & 635 \\
\hline C & $9 \%$ & 216 \\
\hline White Cast Iron & $0 \%$ & 456 \\
\hline
\end{tabular}

\subsection{Slurry wear test}

Slurry wear test has been carried out in slurry erosion testing machine. A schematic diagram of the slurry erosion testing machine is shown in Fig. 3. A graph of loss in weight per unit surface area of sample is plotted against time, and is shown in Fig. 7. Here $0 \% \mathrm{TiC}$ corresponds to white cast iron. This figure shows that white cast iron ( $0 \% \mathrm{TiC})$ has shown maximum wear rate. Here wear rate is defined as weight loss in sample per unit area of the sample per unit time. White cast iron has been included in the test for comparison purpose as white cast iron is a low cost commonly used wear resistant material in mineral processing and mining industries. 4\% TiC composite-A and 6\% TiC composite-B show minimum wear rate or maximum wear resistance. Wear rate of composite-C containing $9 \%$ $\mathrm{TiC}$ is maximum. In spite of higher $\mathrm{TiC}$ content in the composite, its wear rate is found to be maximum. This is attributed to the presence of graphite flakes and porosity in the casting which is very well reflected in its lower density (Table-3). Since graphite flakes act as micro cracks in the matrix (Fig. 5c) therefore they act as potential sites for the easy removal of material. Porosity is a tiny imperfection in the material it also acts as potential sites for the easy removal of material during wear test when it is present on the surface. Porosity if present inside the material is less harmful. Hardness of composite-C is also found to be lowest hardness (216 VHN).

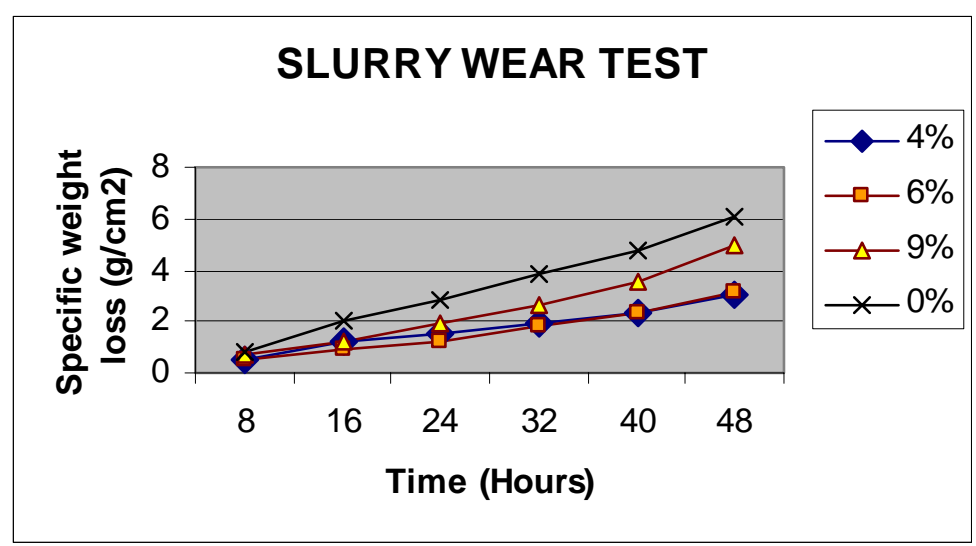

Fig. 7: Variation in weight loss per unit surface area of sample against time. 


\subsection{SEM of worn out surfaces of composites}

Worn out surfaces of specimens of Fe-TiC composites after slury wear test have been studied under SEM and are shown in Fig. 8. It can be observed that materials have been removed by slurry erosion from the regions where graphite (free carbon), porosity or pearlite is present (shown by arrow in the micrographs). Graphite being a soft phase detaches easily from the matrix during slury wear. Pearlite being softer than $\mathrm{TiC}$ and cementite wears out next to graphite. TiC particles and to some extent cementite phase is least harmed. High hardness TiC particles which are strongly bounded to matrix are responsible for low wear of the composite.

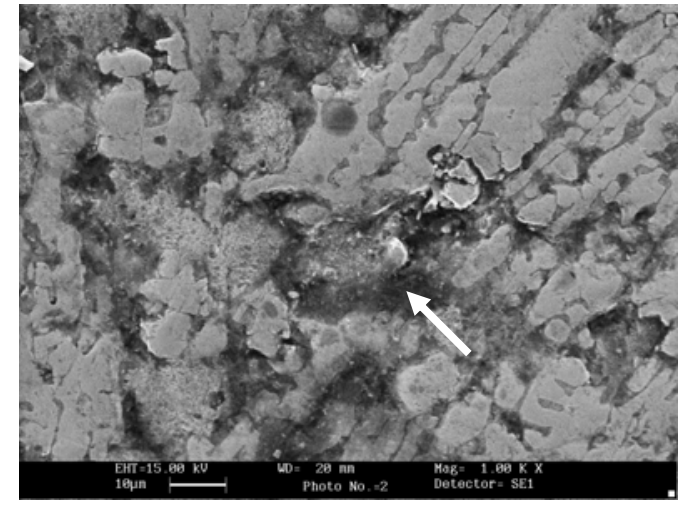

(a)

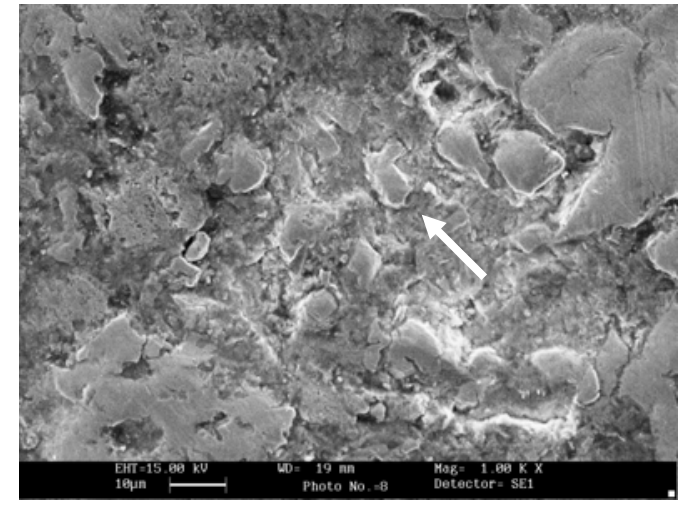

(b)

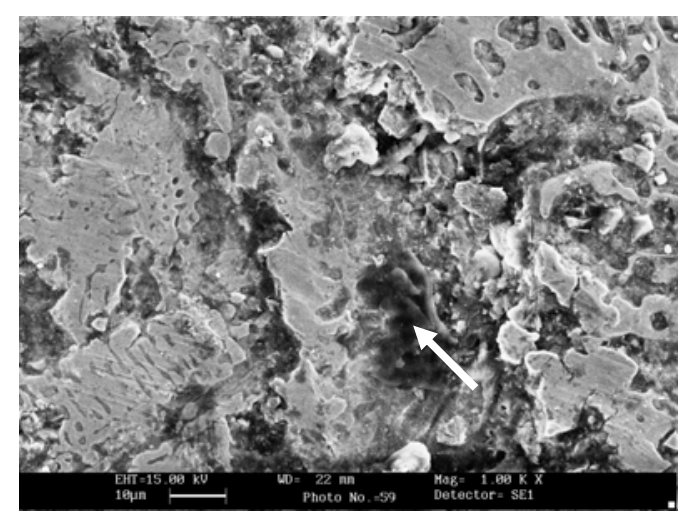

(c)

Fig. 8: SEM micrograph of worn surfaces of composites (a) Composite-A (3000x) (b) CompositeB (3000x) (c) Composite-C (3000x).

\section{Conclusion}

From above study, following conclusion can be drawn:

i) Fe-TiC composites have been synthesized in situ by carbothermic reduction of ilmenite ore concentrate, free carbon, and steel scrap in a plasma reactor in one step.

ii) $\mathrm{Fe}-\mathrm{TiC}$ composites having 4\% $\mathrm{TiC}, 6 \% \mathrm{TiC}$ and $9 \% \mathrm{TiC}$ (by vol.) i.e. Composite-A, Composite-B, and Composite-C respectively, have been synthesized. Incorporation of TiC content greater than $9 \%$ could not be made because of higher viscosity of the melt during pouring.

iii) Presence of excess free carbon during carbothermic reduction appears as graphite in the matrix of transformed ledeburite (pearlite plus cementite).

iv) Microstructure evolved in the composites having $4 \%$ and $6 \% \mathrm{TiC}$, is $\mathrm{TiC}$ particles in transformed ledeburite (pearlite + cementite). Microstructure evolved in the composites having $9 \% \mathrm{TiC}$ is $\mathrm{TiC}$ particles and graphite flakes in transformed ledeburite (pearlite + cementite). Shape of TiC particles is found to be almost rectangular in all the composites prepared. Size of TiC particles are in the range of 2-3 microns and uniformly distributed in the matrix. However some larger TiC particles of size up to about 8 microns have been found in higher concentration of $\mathrm{TiC}(9 \%)$ and are non-uniformly distributed in the matrix.

v) Incorporation of $\mathrm{TiC}$ in the ferrous matrix has improved the hardness and the slury erosion resistance of the composites as compared to white cast iron. As TiC content increases in the composite hardness increases as well as wear resistance increases. 
Maximum sluny wear resistance has been found in the Fe-TiC composite having 6\% TiC (635 VHN). Fe-TiC composite having graphite in the microstructure has shown lesser wear resistance. Porosities in the casting which are exposed to the surface have decreased the slurry wear resistance. Higher hardness, low porosity and absence of graphite flakes have been found to increase slurry wear resistance of TiC reinforced ferrous composites.

\section{References}

Brown, I.W.M and Owers, W.R., (2004): Fabrication, Microstructure and properties of Fe-TiC ceramic metal composites, Current Applied Physics, vol. 4, pp. 171-174.

doi:10.1016/j.cap.2003.11.001

Dogan O.N. and Hawk, J.A. (1995): Abrasion Resistance of In Situ Fe-TiC Composites, Scripta Metallurgica et Materialia, vol. 33, No. 6, pp. 953-958. doi:10.1016/0956-716X(95)00306-G

Galgali, R.K. Ray, H.S. and Chakarabarti, A.K. (1998): A Study on Carbothermic Reduction of Ilmenite Ore in a Plasma Reactor, Metallurgical and materials transaction B, vol. 29B, pp 1175-1180.

Kattamis, T. Z., and Sugan, T., (1990): Solidification processing and tribological behavior of particulate TiCFerrous matrix composites, Material Science and Engineering A, 128, pp.241-252.

doi:10.1016/0921-5093(90)90232-R

Rai, V. K. Nath, S. K. and Ray, S., (1994): Wear behaviour of cast Fe-TiC composites, Proc. IX ${ }^{\text {th }}$ ISME conf, Ajay Printers and Publishers, Roorkee, India, pp. 407-412.

Raghunath, C., Bhatt, M.S. and Rohatgi, P.K. (1995): In situ technique for synthesizing Fe-TiC Composites, Scripta Metallurgica et Materialia, vol. 32, No. 4, pp. 577-582.

doi:10.1016/0956-716X(95)90840-G

Rai, V. K., Nath, S. K. and Ray, S., (1999): Wear in cast titanium carbide reinforced ferrous composites under dry sliding, Wear, vol. 231, pp. 265-27.

Smith, R. W., Gentener, D., Harzenski, E., and Robisch, T.(1988): The structure and properties of plasma sprayed TiC dispersion hardened coatings, Thermal Spray Technology-New Ideas and Processes, Proc. National Thermal Spray Conference, ASM Int., OH, USA, pp.300-306.

Terry, B. S., Chinyamakobvu, O. S., (1991): In situ production of Fe-TiC composites by reactions in liquid iron alloys, J. Material Science Letters, 10, pp.628-629. doi:10.1016/S0043-1648(99)00127-1

Wang, X.H. Zhang, M., DZou, Z., Song, S.L., Han, F and Qu, S.Y., (2006): In situ production of Fe-TiC Surface coatings by tungsten inert gas heat source, Surface \& Coatings Technology,200, pp.6117-6122. doi:10.1007/BF00723359

Wang, Yisan, Zhang, Xinyuan., Li, Fengchun and Zeng, Guangting., (1999): Study on an Fe-TiC surface composite produced in situ, Materials and Design, vol. 20,pp. 233-236.

doi:10.1016/j.surfcoat.2005.09.021

Wang, Yisan, Zhang, Xinyuan, Zeng, Guangting and Li, Fengchun,(2000): Cast sinter technique for producing iron based surface composites, Materials and design, vol. 21, pp. 447-452. 